\title{
Photocatalytic Degradation of Phenolics by N-Doped Mesoporous Titania under Solar Radiation
}

\author{
Priti A. Mangrulkar, ${ }^{1}$ Sanjay P. Kamble, ${ }^{2}$ Meenal M. Joshi, ${ }^{1}$ Jyotsna S. Meshram, ${ }^{3}$ \\ Nitin K. Labhsetwar, ${ }^{1}$ and Sadhana S. Rayalu ${ }^{1}$ \\ ${ }^{1}$ Environmental Materials Unit, National Environmental Engineering Research Institute (CSIR-NEERI), Nagpur 440 020, India \\ ${ }^{2}$ Chemical Engineering and Process Development Division, National Chemical Laboratory (NCL), Pashan Road, Pune 411008, India \\ ${ }^{3}$ P.G. Department of Chemistry, Rashtrasant Tukadoji Maharaj, Nagpur University, Nagpur 440 033, India
}

Correspondence should be addressed to Sadhana S. Rayalu, s_rayalu@neeri.res.in

Received 6 January 2011; Accepted 5 March 2011

Academic Editor: Jinlong Zhang

Copyright ( 2012 Priti A. Mangrulkar et al. This is an open access article distributed under the Creative Commons Attribution License, which permits unrestricted use, distribution, and reproduction in any medium, provided the original work is properly cited.

In this study, nitrogen-doped mesoporous titania was synthesized by templating method using chitosan. This biopolymer chitosan plays the dual role of acting as a template (which imparts mesoporosity) and precursor for nitrogen. BET-SA, XRD, UV-DRS, SEM, and FTIR were used to characterize the photocatalyst. The doping of nitrogen into $\mathrm{TiO}_{2}$ lattice and its state was substantiated and measured by XPS. The photocatalytic activity of the prepared N-doped mesoporous titania for phenol and $o$-chlorophenol degradation was investigated under solar and artificial radiation. The rate of photocatalytic degradation was observed to be higher for $o$-chlorophenol than that of phenol. The photodegradation of $o$-chlorophenol was $98.62 \%$ and $72.2 \%$, while in case of phenol, degradation to the tune of $69.25 \%$ and $30.58 \%$ was achieved in solar and artificial radiation. The effect of various operating parameters, namely, catalyst loading, $\mathrm{pH}$, initial concentration and the effect of coexisting ions on the rate of photocatalytic degradation were studied in detail.

\section{Introduction}

Photocatalysis is a rapidly evolving and efficient technology for purification of water. It plays a vital role in degrading several toxic organic pollutants into less toxic or nontoxic and safe compounds by their partial and/or by their complete mineralization. Photocatalytic degradation process can be defined broadly as an aqueous phase oxidation process, which is based primarily on the attack of the hydroxyl radical, resulting in the destruction of the target pollutant or contaminant compound. Phenol and its derivatives have been listed by EPA as priority pollutants [1]. Recently, photocatalytic treatment of organic contaminants over titanium dioxide has been reviewed by Gaya and Abdullah [2]. It was reported that $\mathrm{TiO}_{2}$ is the best photocatalyst among all the photocatalysts. Moreover, $\mathrm{TiO}_{2}$ has been the most widely used photocatalyst owing to its nontoxicity, high stability, and its cost effectiveness. But there are few drawbacks associated with it like conventional $\mathrm{TiO}_{2}$ which has very low surface area $\left(55 \mathrm{~m}^{2} / \mathrm{g}\right.$ for Degussa P-25 $\left.\mathrm{TiO}_{2}\right)$ and low porosity and it can be activated only by irradiating with ultraviolet light (wide band gap energies, $3.0 \mathrm{eV}$ for rutile and $3.2 \mathrm{eV}$ for anatase) which is around $4-8 \%$ of solar radiation that reaches the earth surface. It is therefore of utmost importance to make $\mathrm{TiO}_{2}$ active in visible region. Sensitization of $\mathrm{TiO}_{2}$ by metal and nonmetal doping is one of the attempts in this direction. Nitrogen-doped titania has proved to be an effective means to extend the light absorption of titania from UV to visible region as in case of nitrogen doped titania there is substitution of lattice oxygen with nitrogen which tends to lower the band gap [3-6]. In recent years several efforts have been made to improve the surface area of titania by synthesizing mesoporous titania which possess high surface area and porosity. The preparation of mesoporous titania is reported by using a templating method. Templates are soft like surfactant or block polymer or they could be hard templates like porous silica and carbon [7-10]. Biological templates like insect wings, plant leaves, 
bacterial threads, and so forth, have also been reported for the synthesis of mesoporous titania [11-13]. Mesoporous titania with visible light absorption ability are promising as efficient photocatalysts. However, the usual preparation route of mesoporous titania and nitrogen doping is different, hence it is difficult to synthesize nitrogen-doped mesoporous titania by a simple route. Synthesizing mesoporous titania with nonmetal doping like nitrogen to enhance visible light activity seems to be promising area of research. Recently, one step-template-free solvothermal method to synthesize $\mathrm{N}$-doped mesoporous titania microspheres was reported by Chi et al. [14], whereby mesoporous spheres were formed by crystallite aggregation from controlled alcoholysis of titania precursor and then reacting urea with titania to dope nitrogen in mesostructure. Horikawa et al. [15] also reported the synthesis of $\mathrm{N}$-doped mesoporous titania by supercritical drying technique.

In continuation with our previous work wherein we had reported the photo reduction of methyl orange dye by $\mathrm{N}$ doped mesoporous titania, herein we investigated the photo oxidation properties of the synthesized photocatalyst. The photocatalyst has shown promising activity in phenol and $o$ chlorophenol photodegradation under visible light.

\section{Experimental}

2.1. Materials. All the reagents used for experimental studies were of analytical reagent grade. Methanol, acetic acid, ammonia, phenol, $o$-chlorophenol, sodium chloride, sodium carbonate, and sodium bicarbonate were obtained from Merck India ltd. Chitosan was procured from Chemchito India. Titanium isopropoxide was obtained from Acros India ltd. The stock solutions of phenol and $o$-chlorophenol were prepared in deionized water obtained from Millipore waters progard 2 purification system. Plain solar intensity was measured in Watts per square meter using Lutron LX-102 light meter working on photocell principle.

2.2. Method. All the experiments were carried out in a cylindrical borosilicate glass reactor of $500 \mathrm{~cm}^{3}$ capacity (Figure 1). The reactor was assembled with centrally mounted sparger surrounded by cooling coil. The same experimental setup was employed in the present investigation which was previously used by Kamble et al. [16]. The temperature of the reaction mixture was maintained near ambient by passing water through the cooling coil. $400 \mathrm{~cm}^{3}$ of solution (phenol/o-chlorophenol) was taken in the reactor and a known weight of the photocatalyst was added to the reactor. The solution was stirred in dark before exposing the reactor to concentrated sunlight from a compound parabolic reflector in order to find out the substrate adsorption effect. The concentration of phenol or $o$-chlorophenol in this filtered sample was treated as the zero time concentration $(\mathrm{Ct}=0)$ in each experiment before exposure to radiation. Air was sparged in the reactor through central sparger in order to keep the photocatalyst particles in uniform suspension. The position of the reflector was changed after a fixed interval of time with respect to the position of sunlight in order

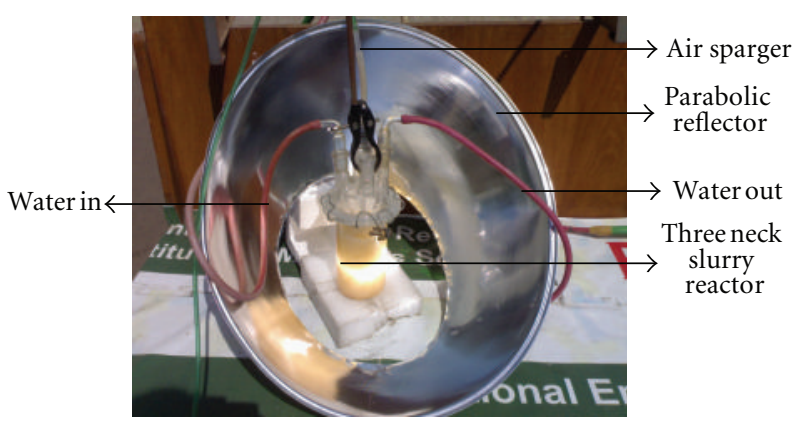

FIGURE 1: Experimental setup of the solar reactor for photocatalytic degradation experiment.

to maintain a constant band of light around the reactor. Samples were withdrawn at regular intervals of time for their analysis.

2.3. Analysis. All the samples were withdrawn using a syringe, centrifuged, and then were immediately filtered through $0.45 \mu$ cellulose nitrate membranes. The phenol and $o$-chlorophenol concentration was measured on Knauer HPLC system equipped with Eurospher 100-10 C-18 column. The wavelength for detection of phenol and $o$-chlorophenol was $270 \mathrm{~nm}$ and $274 \mathrm{~nm}$, respectively. The mobile phase used for analysis was methanol: water $(50: 50) \mathrm{v} / \mathrm{v} \%$ and the flow rate was $1.2 \mathrm{~cm}^{3} \mathrm{~min}^{-1}$. The elution time for phenol and $o$-chlorophenol was 4.2 and $8.3 \mathrm{~min}$, respectively. The solar experiments were carried out in the months of January 2008 to April 2008 in Nagpur, India $\left(79^{\circ} 09^{\prime} \mathrm{N}, 21^{\circ} 09^{\prime} \mathrm{E}\right)$. During this period, the sky was brilliant blue, and the average solar intensity was approximately $( \pm 2 \%)$ constant at $950 \mathrm{Wm}^{-2}$ as measured at the ground level. The experiments in artificial radiations were also carried out during the same period using Tungsten lamp $(500 \mathrm{~W})$.

2.4. Synthesis of N-Doped Mesoporous Titania. The synthesis of $\mathrm{N}$-doped mesoporous titania has been previously reported by us and detailed elsewhere [17]. The ratio of chitosan and titania was changed to obtain mesoporous titania with different nitrogen content namely, N-doped M-TiO 2 (1:1) and N-doped $\mathrm{M}-\mathrm{TiO}_{2}(1: 2)$ and N-doped $\mathrm{M}-\mathrm{TiO}_{2}$ (1:3). The photocatalytic activity of all the three synthesized photocatalysts was evaluated for 0 -chlorophenol degradation. The $\%$ degradation of $o$-chlorophenol under solar radiation is as shown in Figure 2. It can be seen that highest percentage degradation was observed in case of $\mathrm{N}$ doped $\mathrm{M}^{-\mathrm{TiO}_{2}}(1: 2)$ followed by $\mathrm{N}$-doped $\mathrm{M}^{-\mathrm{TiO}_{2}}(1: 3)$ and $\mathrm{N}$-doped $\mathrm{M}^{-\mathrm{TiO}_{2}}(1: 1)$. The visible light activity of these photocatalysts is attributed to the nitrogen doping. The nitrogen partially replaces oxygen sites in $\mathrm{TiO}_{2}$. This replacement causes oxygen vacancies and amount of $\mathrm{Ti}^{3+}$ ( $\mathrm{TiO}_{2}$ is reduced). These defects on the surface or in the bulk suppresses recombination reaction. The presence of optimal nitrogen content is crucial because excessive oxygen 


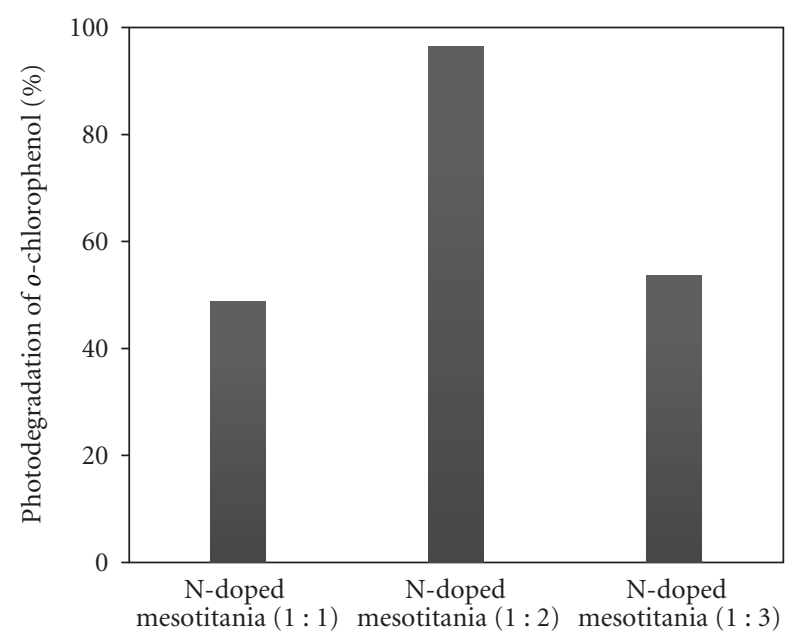

FIgURE 2: Comparison of the percentage degradation of $o$ chlorophenol by $\mathrm{N}$-doped mesoporous titania (1:1), N-doped mesoporous titania $(1: 2)$ and $\mathrm{N}$-doped mesoporous titania $(1: 3)$.

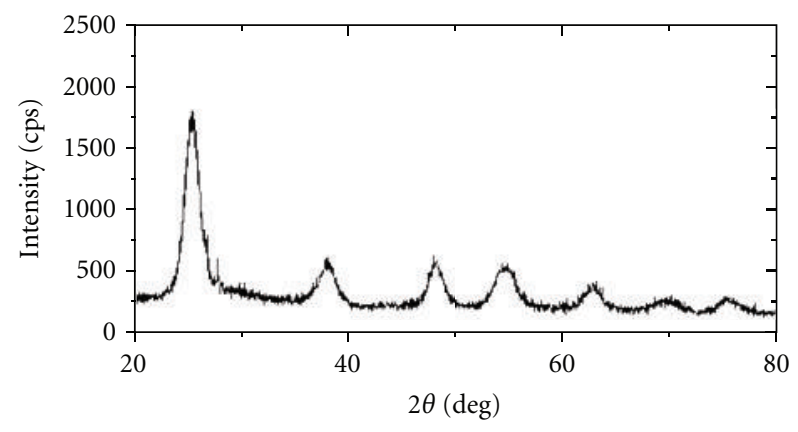

FIGURE 3: XRD spectra of N-doped mesoporous titania.

vacancies and $\mathrm{Ti}^{3+}$ may act as recombination centre. Thus, further studies were carried out by $\mathrm{N}$-doped $\mathrm{M}-\mathrm{TiO}_{2}(1: 2)$.

\section{Results and Discussion}

3.1. Characterization of N-Doped Mesoporous Titania. The BET surface area of the synthesized photocatalyst was determined by specific surface area analyzer (ASAP 2000, micrometics) with nitrogen gas as the adsorbate. The surface area of $\mathrm{N}$-doped mesoporous titania was found to be $132.36 \mathrm{~m}^{2} / \mathrm{g}$ which is significantly higher as compared to the conventional titania Degussa P-25 $\left(55 \mathrm{~m}^{2} / \mathrm{g}\right)$. The pore size was determined by $\mathrm{BJH}$ method and the pore size was found to be $49.68 \AA$. It can be clearly seen that the photocatalyst is mesoporous in nature and possesses high surface area.

Powder XRD diffraction patterns of N-doped mesoporous titania were carried out on Rigaku Miniflex II desktop $\mathrm{X}$-ray diffractometer with $\mathrm{CuK} \alpha$ radiation, as shown in Figure 3 . The scanning range of $2 \theta$ was set to between $20^{\circ}$ and $80^{\circ}$. It can be seen from the X-ray diffraction patterns that all peaks can be indexed as the anatase phase $\left(25.6^{\circ}\right.$, $37.08^{\circ}, 48^{\circ}, 55.4^{\circ}$, and $63.32^{\circ}$ ) of titania. The low angle peaks $\left(1^{\circ}-3^{\circ}\right)$ characteristic of ordered mesoporous structure were not observed [18].

The Fourier Transform Infrared (FTIR) analysis was carried on Bruker Vertex-70 by Diffuse Reflectance Accessory technique. The FTIR spectra of N-doped mesoporous titania are as shown in Figure 4. The peaks corresponding to $\mathrm{N}-\mathrm{H}$ stretching $\left(3690.73 \mathrm{~cm}^{-1}\right)$ and $\mathrm{NH}_{2}\left(1573.12 \mathrm{~cm}^{-1}\right)$ indicate the presence of nitrogen in the synthesized photocatalyst. The peak at $2918.44 \mathrm{~cm}^{-1}$ is attributed to $=\mathrm{C}-\mathrm{H}_{2}$ stretching vibrations, while the peak at $1676.52 \mathrm{~cm}^{-1}$ corresponds to $\mathrm{C}=\mathrm{C}$ stretching vibrations.

Diffuse reflectance UV-Vis spectra of the synthesized photocatalyst was recorded using a Perkin Elmer spectrophotometer lambda 900 equipped with an integrating sphere. $\mathrm{BaSO}_{4}$ was used as a reference material. The spectrum is as shown in Figure 5. The absorption maxima of $\mathrm{N}$ doped mesoporous titania was found to be $466.66 \mathrm{~nm}$, which corresponds to the visible range of the spectrum indicating that $\mathrm{N}$-doped mesoporous titania is active in visible light. The prominent red shift of the photocatalyst as compared to Degussa P-25 $\mathrm{TiO}_{2}$ can be attributed to the presence of nitrogen. The band gap energy was calculated from the absorption maxima by using following equation:

$$
\mathrm{Eg}(\mathrm{eV})=1240 / \lambda \mathrm{g} \mathrm{nm}
$$

(see [19]), where $\lambda g$ is absorption maxima. The band gap energy was found to be $2.65 \mathrm{eV}$.

Chemical composition analysis using energy dispersive $\mathrm{X}$-ray (EDX) spectroscopy is as shown in Figure 6. From the EDX spectra the nitrogen content of $\mathrm{N}$-doped mesoporous titania was found to be 0.72 mass percent.

The morphology of the sample was investigated by scanning electron microscopy (SEM). Figure 7 shows the SEM images of $\mathrm{N}$-doped mesoporous titania with different magnifications. As it can be seen from the images, Ndoped mesoporous titania particles exhibit an irregular morphology. The particle size for synthesized mesoporous titanai was measured by using CILAS-1180 instrument and it was observed to be $3.450 \mu \mathrm{m}$.

The X-ray photoelectron spectroscopy measurements were carried out on VG Microtech ESCA 3000 instrument at a pressure of $>1 \times 10^{-9}$ Torr. The general scan, $\mathrm{C}_{1 \mathrm{~s}}$, $\mathrm{O}_{1 s}, \mathrm{~N}_{1 s}$, and $\mathrm{Ti}_{2 \mathrm{p}}$ core level spectra were recorded with non-monochromatized $\mathrm{Mg} \mathrm{K} \alpha$ radiation (photon energy $1253.6 \mathrm{eV}$ ) at a pass energy of $50 \mathrm{eV}$ and an electron takeoff angle (angle between electron emission direction and surface plane) of $55^{\circ}$. The overall resolution was $0.2 \mathrm{eV}$ for XPS measurements. The core level spectra were background-corrected using the Shirley algorithm, and chemically distinct species were resolved using nonlinear least-squares fitting procedure. Baseline correction and peak fitting for the sample was done using the software package XPS peak 41. The core level binding energies (BEs) were aligned with respect to the $C_{1 s}$ binding energy of $285 \mathrm{eV}$.

The doping of nitrogen into $\mathrm{TiO}_{2}$ lattice, and its state was substantiated and measured by XPS. Figure 8 illustrates the $\mathrm{O}_{1 \mathrm{~s}}, \mathrm{Ti}_{2 \mathrm{p}}, \mathrm{N}_{1 \mathrm{~s}}$, and $\mathrm{C}_{1 \mathrm{~s}}$ spectra of $\mathrm{N}$-doped mesoporous titania $(1: 2)$. In N1s XPS spectra two signals at $\mathrm{BE}=394.2 \mathrm{eV}$ 


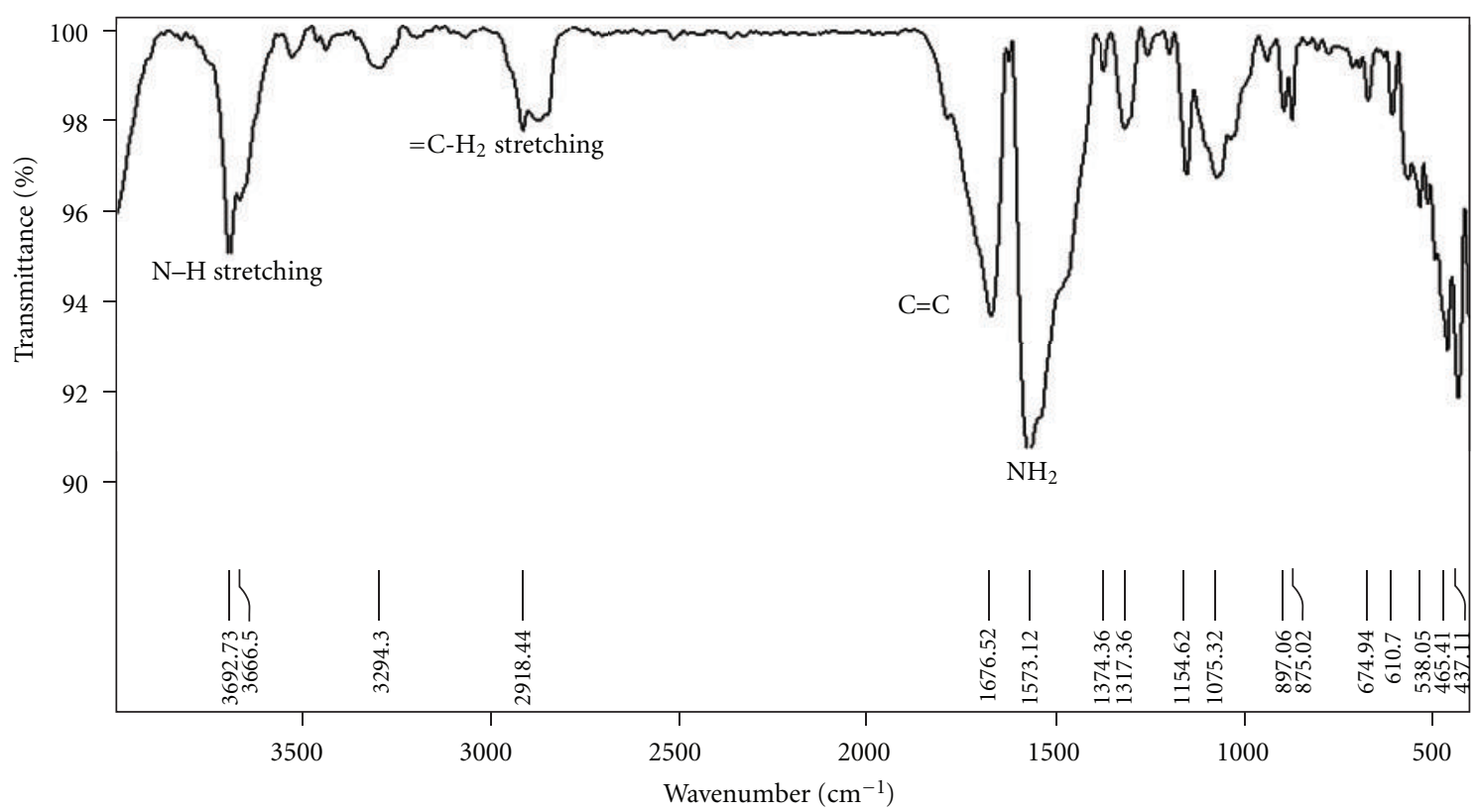

FIGURE 4: FTIR spectra of N-doped mesoporous titania.

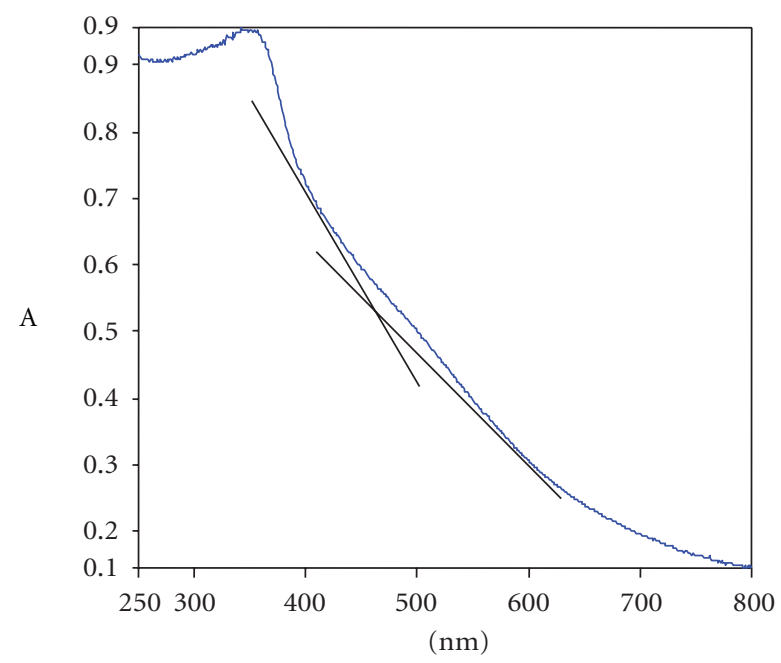

FIgURE 5: UV-Vis spectra of N-doped mesoporous titania.

and $400.9 \mathrm{eV}$ can be observed. The peak at $394.2 \mathrm{eV}$ belongs to $\beta \mathrm{N}$ state, and it generally attributes to the presence of $\mathrm{Ti}-\mathrm{N}$ bond whereby the $\mathrm{N}$ atoms replace the oxygen atoms in $\mathrm{TiO}_{2}$ lattice, while the second peak at $400.9 \mathrm{eV}$ may be due to molecularly adsorbed nitrogen containing compound on the surface. The spectra obtained are quite consistent with those observed by Horikawa et al. [15]. The presence of titania ion in an octahedral environment is indicated by major peak which is centred at $462.3 \mathrm{eV}$ in the $\mathrm{Ti}_{2 \mathrm{p}}$ spectra. There is a single major peak that is observed at $534.5 \mathrm{eV}$ in case of $\mathrm{O}_{1 \mathrm{~s}}$, which corresponds to Ti-O bond. In case of $\mathrm{C}$ spectra two major peaks are seen at $285.6 \mathrm{eV}$ and $289.8 \mathrm{eV}$ which are indicative of the presence of $\mathrm{C}-\mathrm{O}$ and $\mathrm{C}=\mathrm{O}$ bond. The characteristic peak at $281 \mathrm{eV}$ which corresponds to Ti-C
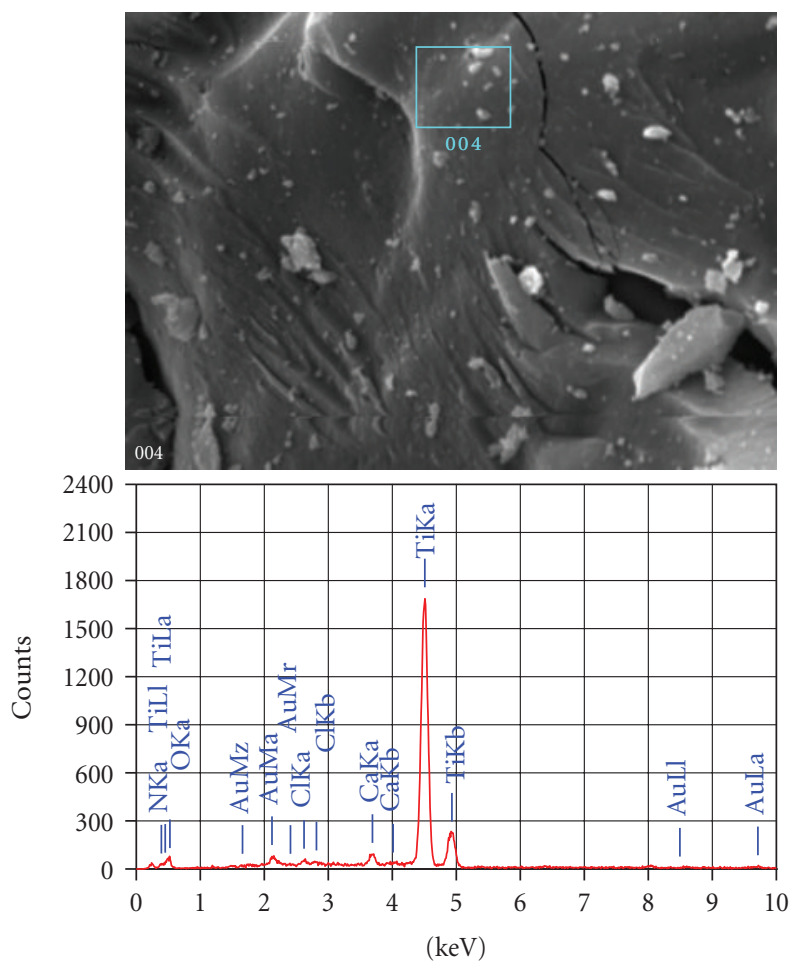

FIGURE 6: EDX spectra of N-doped mesoporous titania.

bond was not observed which suggests that carbon atoms do not replace the oxygen atoms in the $\mathrm{TiO}_{2}$ lattice.

Comparison of N-Doped Mesoporous Titania with Degussa $P-25 \mathrm{TiO}_{2}$. The preliminary photodegradation experiments were carried out under identical set of conditions under 


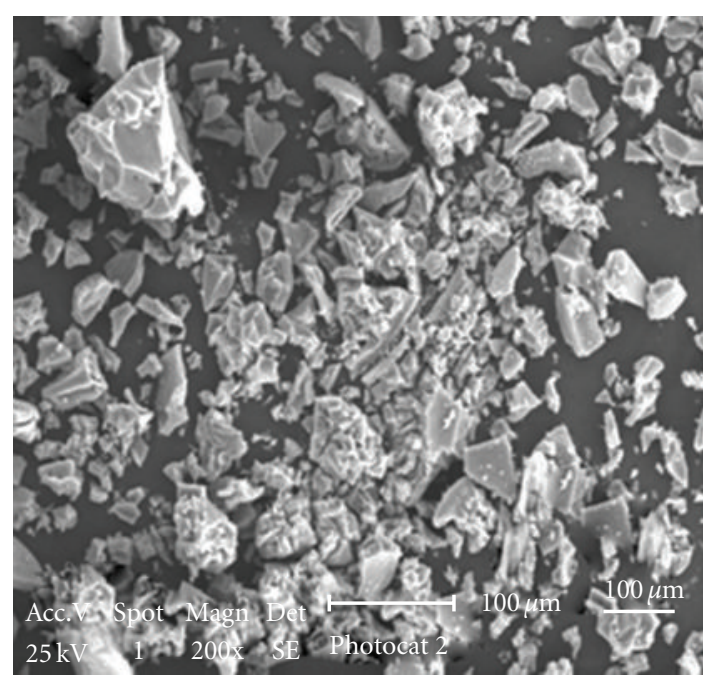

(a)

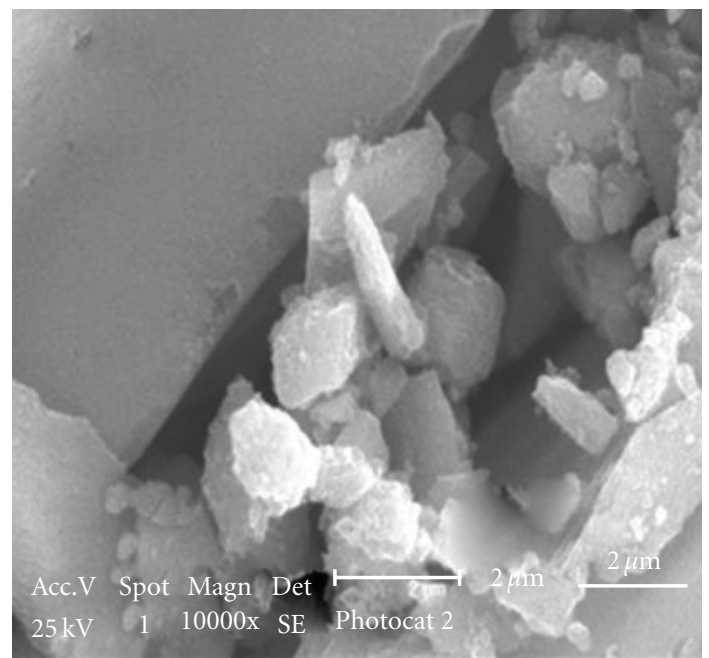

(c)

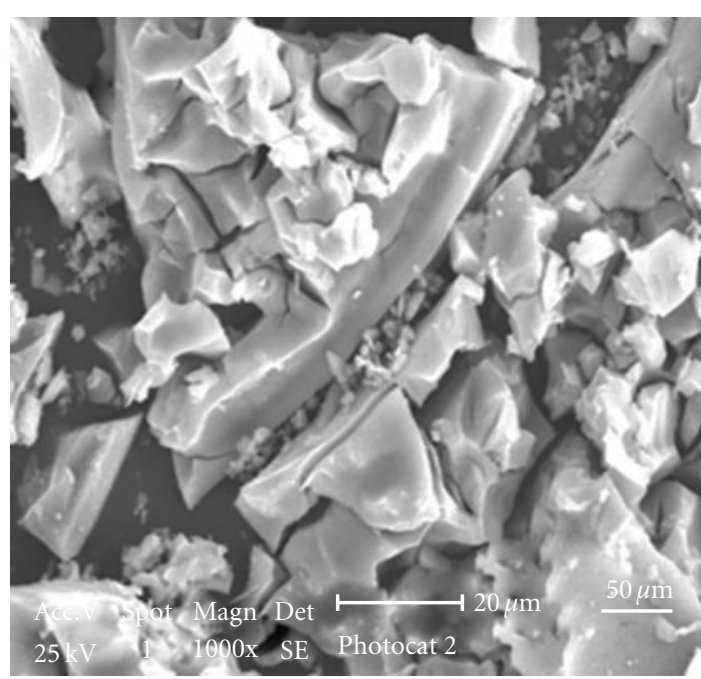

(b)

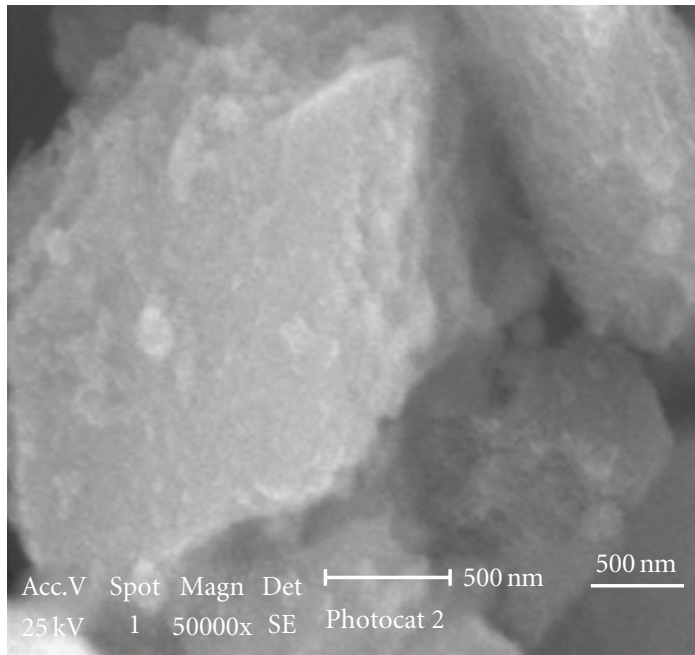

(d)

FIGURE 7: SEM of N-doped mesoporous titania.

solar radiation using commercially available $\mathrm{TiO}_{2}$ (Degussa $\mathrm{P}-25$ ) and $\mathrm{N}$-doped mesoporous titania. The photocatalytic degradation activities of this nondoped $\mathrm{TiO}_{2}$ (Degussa P25 ) were then compared with those of $\mathrm{N}$-doped mesoporous titania. It was observed that $\mathrm{N}$-doped mesoporous titania has significantly higher activity for both phenol as well as o-chlorophenol as compared to Degussa P-25. The comparison of N-doped mesoporous titania with Degussa P-25 is as shown in Figure 9: It was observed that $28.59 \mathrm{mg}$ of phenol degraded/g of $\mathrm{TiO}_{2}$ in case of $\mathrm{N}$-doped mesoporous titania as compared to $24.75 \mathrm{mg}$ phenol degraded/g of $\mathrm{TiO}_{2}$ for Degussa P-25 in solar radiation, while $40.71 \mathrm{mg}$ $o$-chlorophenol degraded/g of $\mathrm{TiO}_{2}$ in case of $\mathrm{N}$-doped mesoporous titania as compared to $24.75 \mathrm{mg} o$-chlorophenol degraded/g of $\mathrm{TiO}_{2}$ for Degussa P-25. The difference in the photodegradation activities in case of $o$-chlorophenol for $\mathrm{TiO}_{2}$ and $\mathrm{N}$-doped $\mathrm{TiO}_{2}$ is significant as compared to phenol.
(1) In case of $\mathrm{N}$-doped mesoporous titania, there is an intense absorption in the visible light range and there is a red shift in the case of $\mathrm{N}$-doped $\mathrm{TiO}_{2}$, resulting in the generation of more photogenerated electrons and holes participating in the photocatalytic reactions under visible light. In case of $o$-chlorophenol the aryl-Cl bond, is a weak bond and it is cleaved with relative ease which further facilitates the attack of - OH radical and hence $o$-chlorophenol is degraded to a greater extent. In case of phenol, as it is resonance stabilized, the photodegradation is to a lesser extent.

(2) Adsorption of the substrate on the photocatalyst has a major role in its photocatalytic degradation. According to the mechanism suggested, the attack of ${ }^{\bullet} \mathrm{OH}$ radicals takes place on the adsorbed substrate [20]. The equilibrium adsorption studies were carried out for both phenol and $o$-chlorophenol. In case of dark 


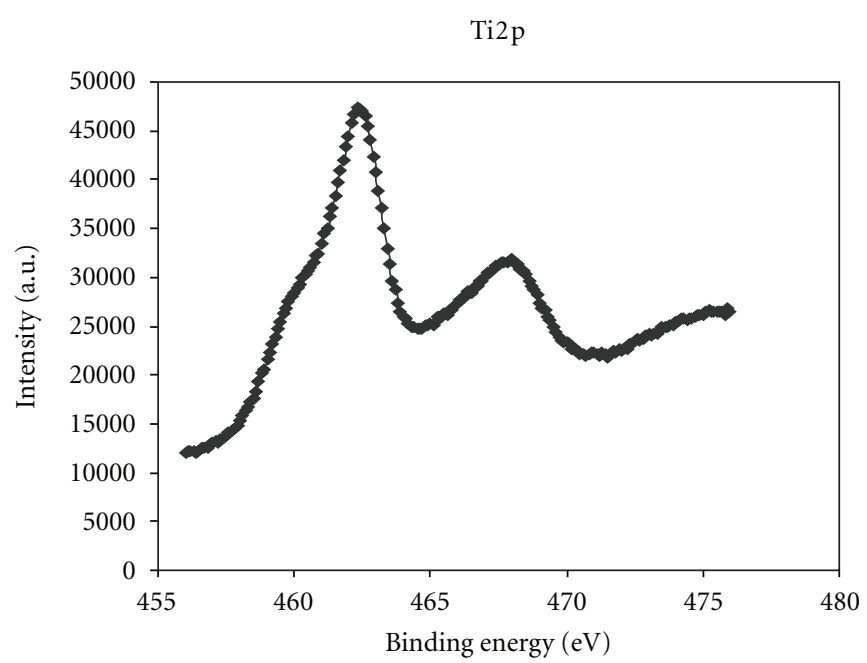

(a)

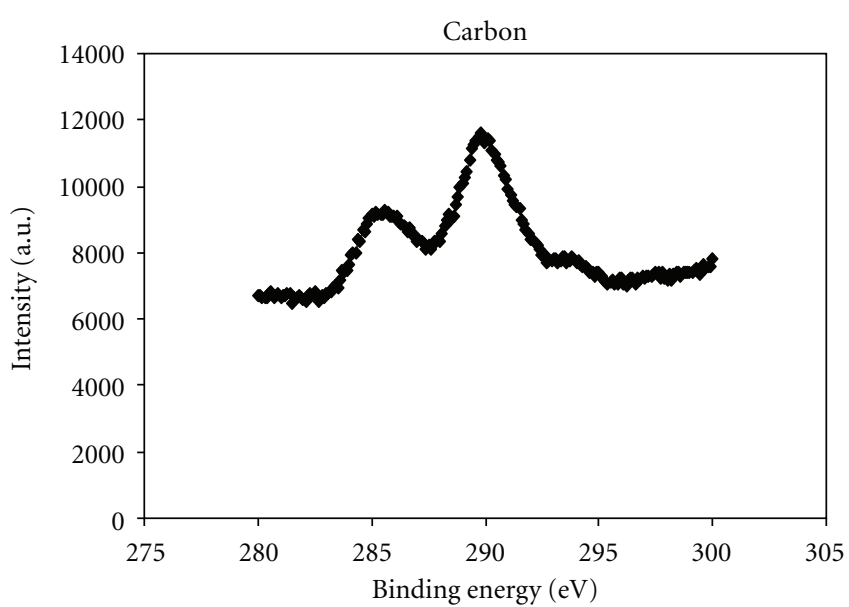

(c)

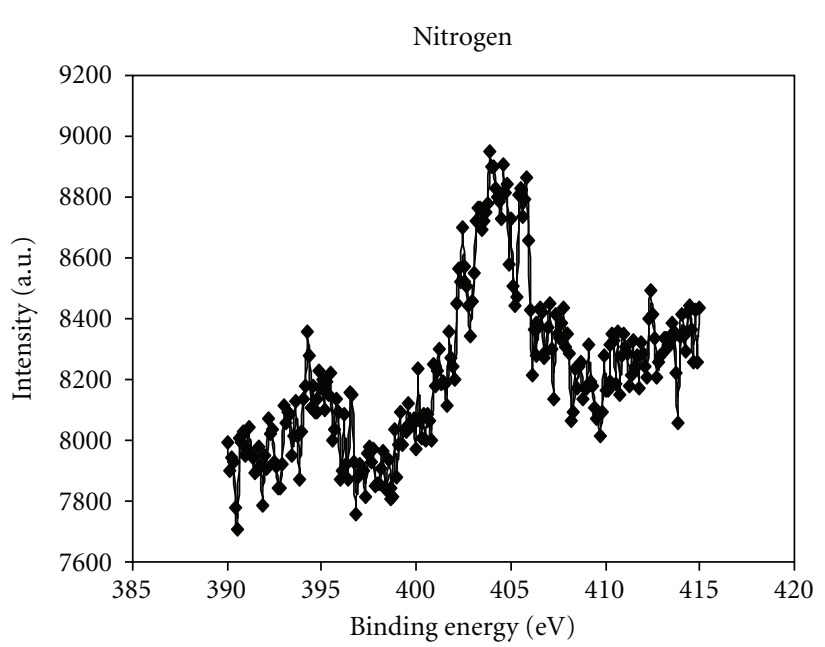

(b)

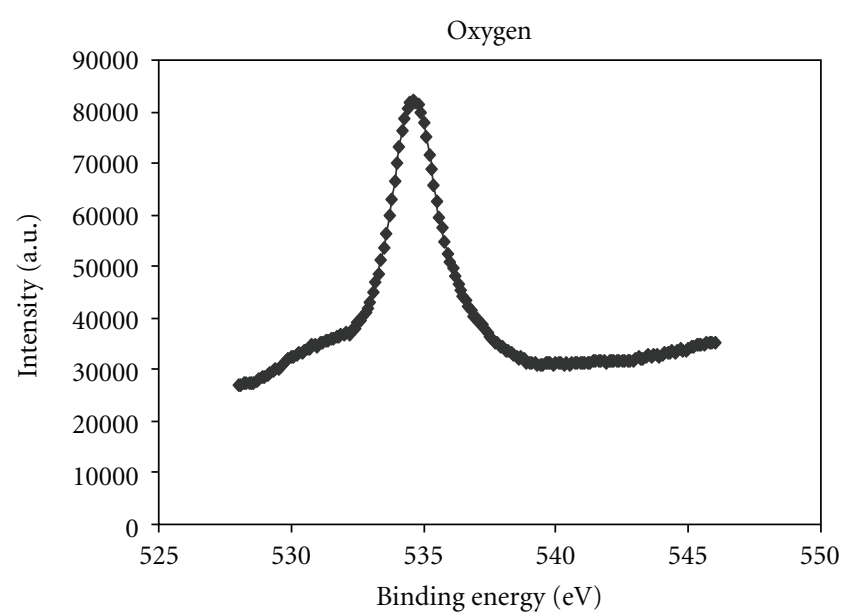

(d)

FIGURE 8: XPS of N-doped mesoporous titania.

adsorption studies, $50 \mathrm{~mL}$ (phenol/o-chlorophenol) were mixed with both $\mathrm{TiO}_{2}$ and $\mathrm{N}$-doped $\mathrm{TiO}_{2}$ and shaken for $24 \mathrm{~h}$ for equilibrium. The adsorption of $o$ chlorophenol was $36 \%$ on $\mathrm{N}$-doped as compared to $15 \%$ for $\mathrm{TiO}_{2}$ resulting in more photodegradation.

\subsection{Effect of Various Parameters on Photocatalytic Degradation}

3.2.1. Effect of Catalyst Loading. The effect of catalyst loading on photocatalytic degradation of phenol and $o$-chlorophenol by $\mathrm{N}$-doped mesoporous titania was studied. The catalyst loading was varied from $0.1 \% \mathrm{w} / \mathrm{v}$ to $0.3 \% \mathrm{w} / \mathrm{v}$. The photocatalytic degradation of phenol and $o$-chlorophenol is as shown in Figures 10(a) and 10(b). It can be seen that initially the photocatalytic degradation for both phenol and $o$-chlorophenol increases linearly as the catalyst loading is increased from $0.1 \% \mathrm{w} / \mathrm{v}$ to $0.2 \% \mathrm{w} / \mathrm{v}$ but when the catalyst loading is increased further to $0.3 \% \mathrm{w} / \mathrm{v}$, the rate of degradation decreases in case of both phenol and $o$ chlorophenol. However, the increase in degradation rate is marginal for phenol as compared to $o$-chlorophenol. The decrease in degradation rate with increase in catalyst loading can be attributed to the increased opacity of the solution which hinders the light transmission through the solution. As a result of decreased effective light intensity, the photo generation of electrons and positive holes would be reduced and then the rate of photocatalytic degradation is also reduced.

3.2.2. Effect of Initial Concentration. Effect of initial concentration on the rate of photocatalytic degradation was studied at different initial concentrations of phenol and $o$ chlorophenol and is as shown in Figures 11(a) and 11(b). It was found that with the increase in initial concentration of phenol and $o$-chlorophenol the rate of degradation decreases. This is because with the increase in concentration the amount of organic species to be degraded increases but the 


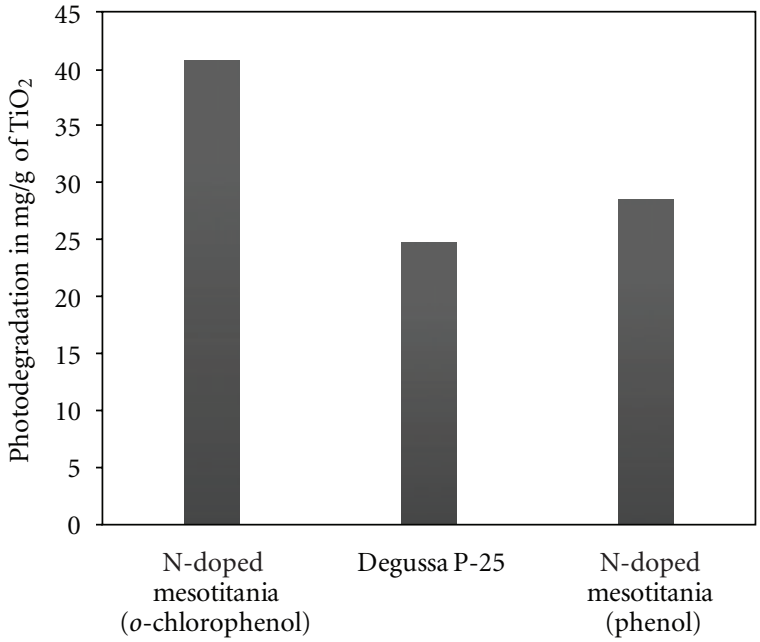

Figure 9: Comparison of $\mathrm{N}$-doped mesoporous titania with Degussa P-25 for photodegradation of $o$-chlorophenol and phenol.

rate of generation of $\mathrm{OH}$ radical, photocatalyst loading, dissolved oxygen concentration, intensity of illumination and illumination time are constant during the photodegradation. Hence with increase in initial concentration the rate of photocatalytic degradation decreases.

3.2.3. Effect of Initial $p H$. The $\mathrm{pH}$ of the solution is an important factor which affects the degradation rate. The effect of initial $\mathrm{pH}$ of solution on the photocatalytic degradation of phenol and $o$-chlorophenol by $\mathrm{N}$-doped mesoporous titania was studied. The $\mathrm{pH}$ of initial solution was varied from 3 to 11 . In acidic range the $\mathrm{pH}$ was varied using $0.1 \mathrm{M} \mathrm{HCl}$ while in alkaline range the $\mathrm{pH}$ was varied using $0.1 \mathrm{M} \mathrm{NaOH}$. The rate of degradation for both phenol and $o$-chlorophenol is as shown in Figures 12(a) and 12(b). It can be seen that in case of both phenol and $o$-chlorophenol, maximum degradation was found to be at $\mathrm{pH}$ 7. In both acidic as well as alkaline ranges the rate of degradation decreases. This can be explained from the fact that $\mathrm{TiO}_{2}$ is amphoteric in nature and the zero point charge of $\mathrm{TiO}_{2}$ is at $\mathrm{pH}-6$. At acidic $\mathrm{pH}$, the surface of $\mathrm{TiO}_{2}$ is positively charged while it is negatively charged at alkaline $\mathrm{pH}$. In case of both phenol and $o$-chlorophenol the photocatalytic degradation decreases in acidic $\mathrm{pH}$ as the adsorption is less at acidic $\mathrm{pH}$, while at alkaline $\mathrm{pH}$, the negatively charged phenolate ions are repelled by the negatively charged surface of $\mathrm{TiO}_{2}$ and hence photocatalytic degradation decreases.

3.2.4. Effect of Coexisting Anions. The industrial effluent may contain several salts at different concentrations. These salts may exert negative or positive influence on the rate of photocatalytic degradation. The effect of various ions like chloride, carbonate, and bicarbonate on the photocatalytic degradation of phenol and $o$-chlorophenol were studied by adding $0.1 \mathrm{M}$ solution of their salts to $50 \mathrm{mgL}^{-1}$ of phenol and $o$-chlorophenol. The effect of the presence of coexisting

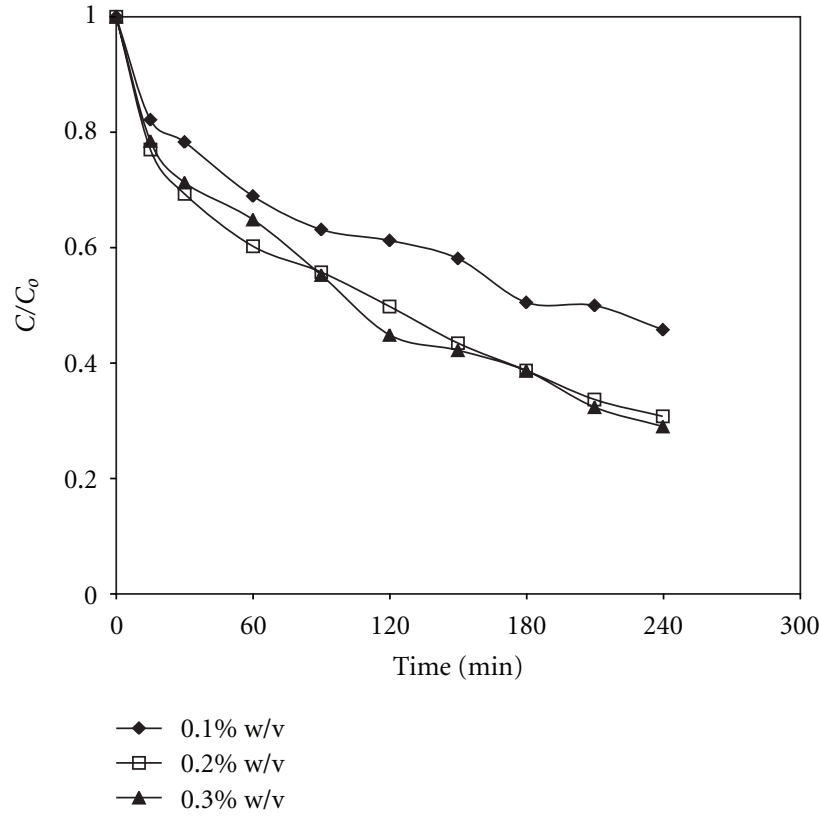

(a)

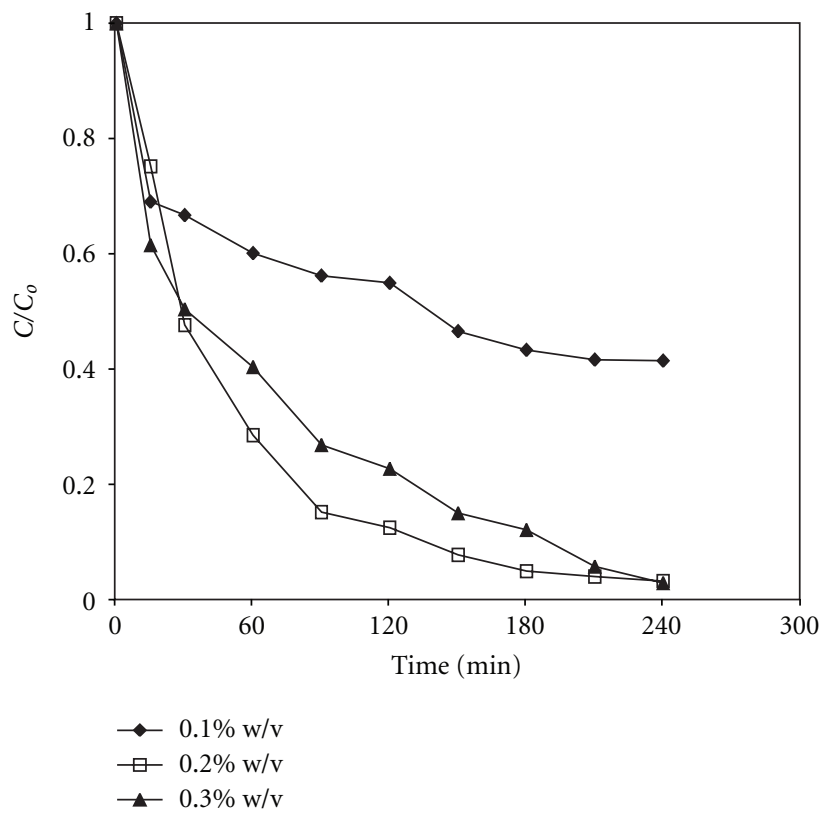

(b)

FIGURE 10: Effect of catalyst loading on photocatalytic degradation: (a) phenol, (b) o-chlorophenol.

anions on photocatalytic degradation of phenol and $o$ chlorophenol is shown in Figures 13(a) and 13(b). It can be clearly seen from these figures that the coions have a detrimental effect on the photocatalytic degradation. In case of phenol, the photocatalytic degradation in the absence of salts was $69.5 \%$, while the photocatalytic degradation in case of sodium chloride, sodium carbonate, and sodium bicarbonate was $49.72 \%, 31.14 \%$, and $35.98 \%$, respectively. Similarly, in case of $o$-chlorophenol the photocatalytic degradation in 


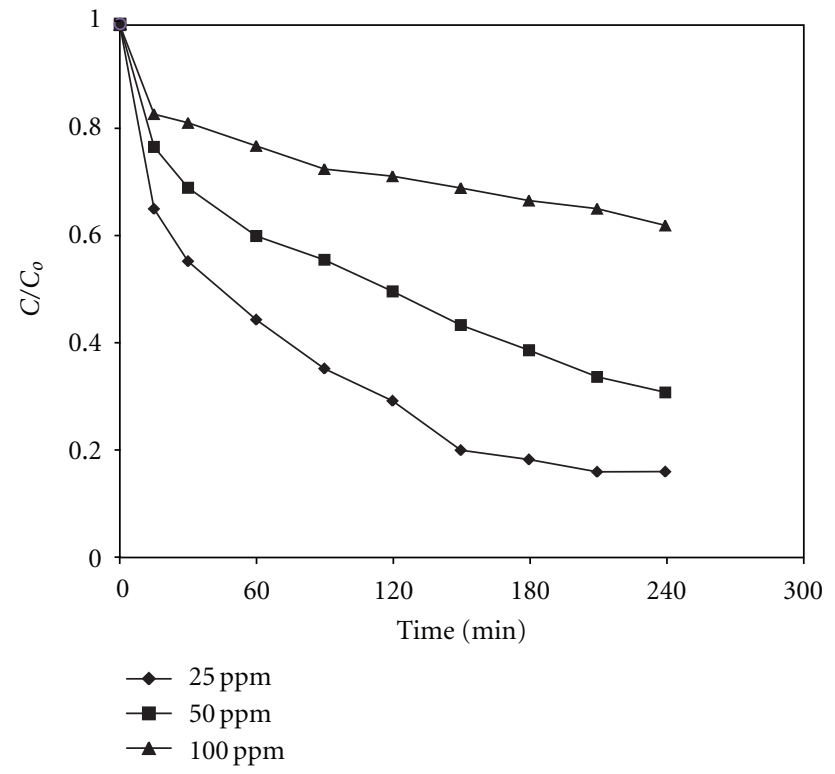

(a)

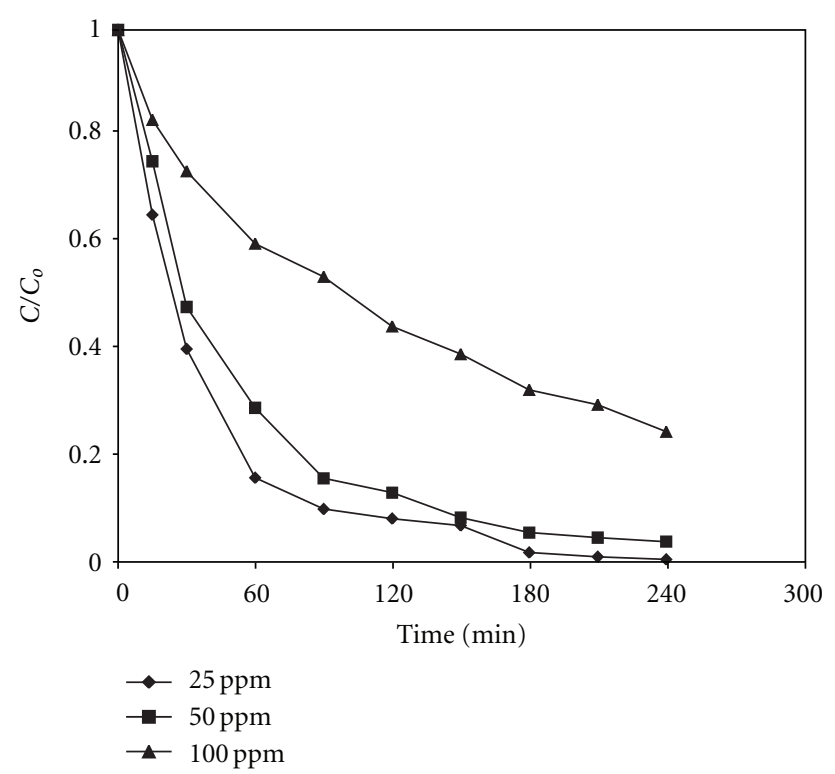

(b)

FIGURE 11: Effect of initial concentration on photocatalytic degradation: (a) phenol, (b) $o$-chlorophenol.

the absence of salts was $98.62 \%$, while the photocatalytic degradation in case of sodium chloride, sodium carbonate, and sodium bicarbonate was $87.09 \%, 79.34 \%$, and $81.90 \%$, respectively. It can be seen that the presence of chloride, carbonate, and bicarbonate has substantial detrimental effect on photocatalytic degradation of phenolics. The negative effect of these anions is attributed to following two reasons: (i) change in $\mathrm{pH}$ after addition of salts in aqueous solution of substrate (from acidic to alkaline).This contributes to inhibition of photocatalytic degradation of phenol and $o$ chlorophenol (Figures 12(a) and 12(b) also show the same trend.). (ii) Carbonate and bicarbonate anions basically act

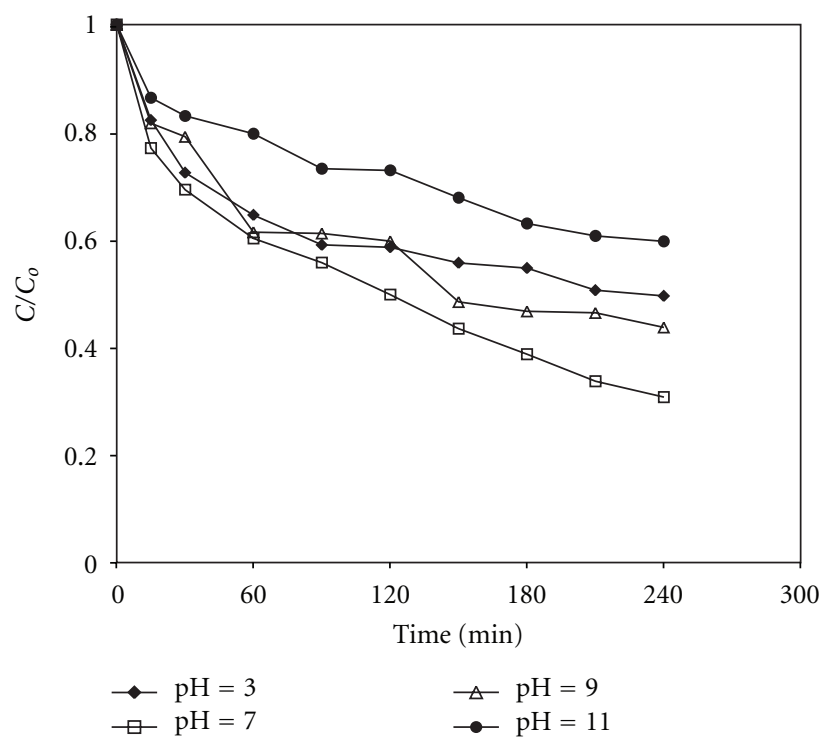

(a)

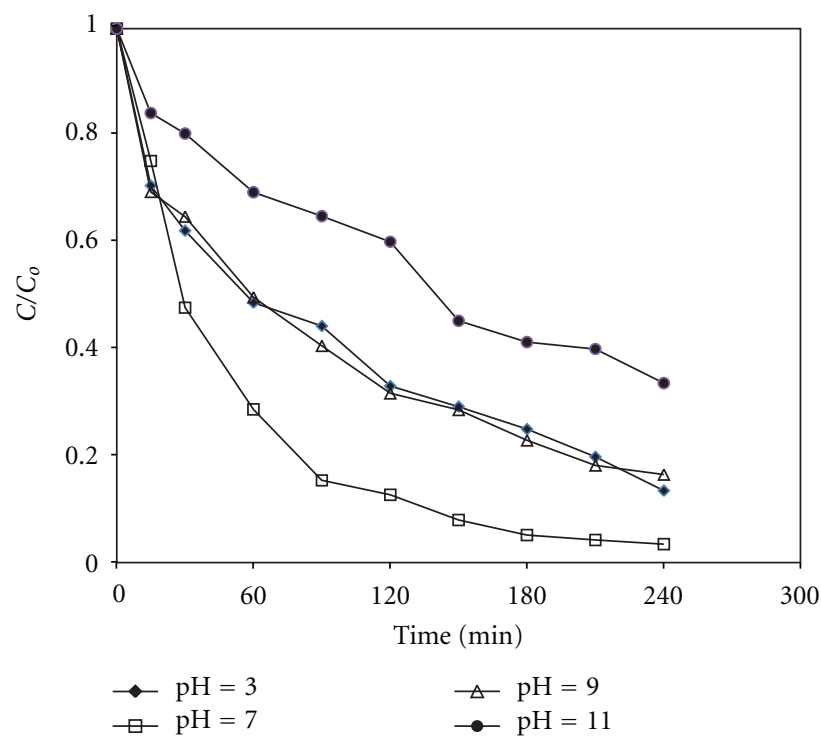

(b)

FIGURE 12: Effect of initial $\mathrm{pH}$ on photocatalytic degradation (a) phenol (b) o-chlorophenol.

as hydroxyl radical scavengers, which affect photocatalytic degradation of phenol and $o$-chlorophenol. The decrease in the degradation rate in case of $\mathrm{NaCl}$ may be attributed to the poor adsorption.

3.3. Identification of Intermediates. The intermediates formed during the photocatalytic degradation of phenol and o-chlorophenol were identified by High Pressure Liquid Chromatograph. The intermediates formed in case of photocatalytic degradation of phenol were catechol ( 1 to $8 \mathrm{mg} / \mathrm{L}$ ), hydroquinol $(0.2$ to $0.7 \mathrm{mg} / \mathrm{L})$, and benzoquinone $(0.5$ to $2 \mathrm{mg} / \mathrm{L}$ ), while in case of $o$-chlorophenol the major 


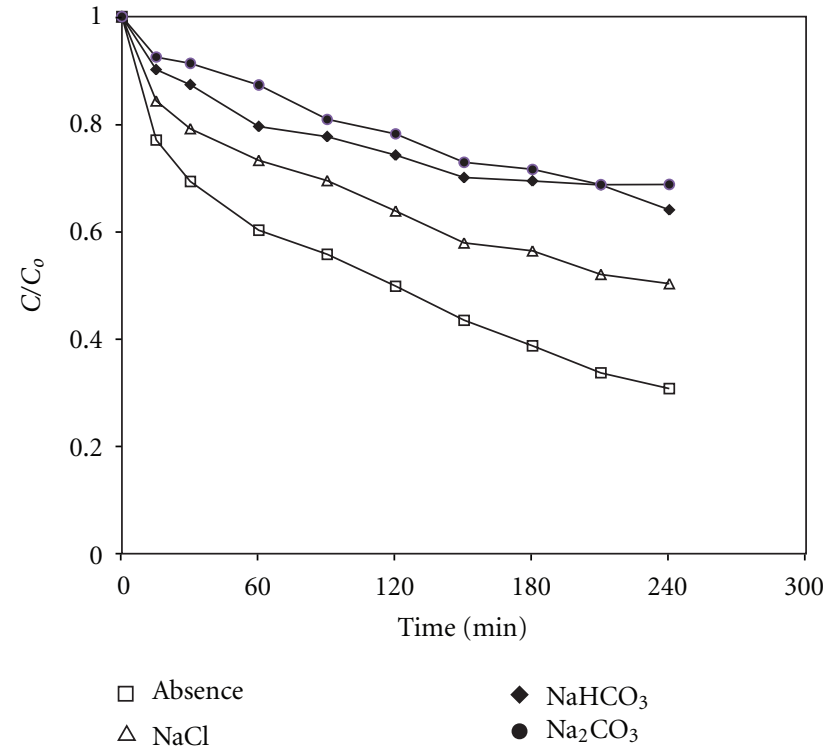

(a)

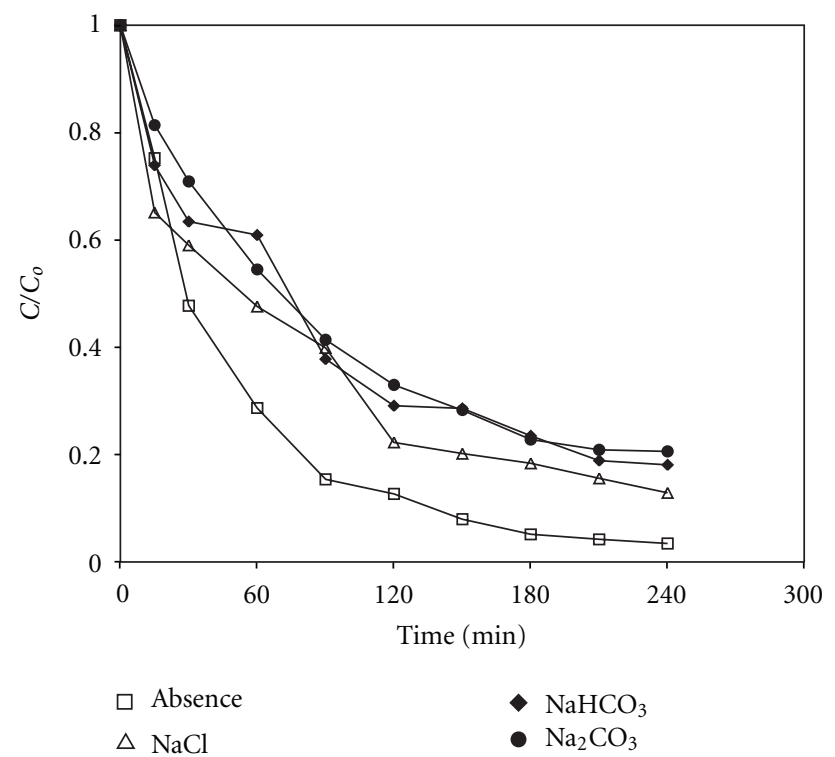

(b)

FIGURE 13: Effect of presence of coexisting ions on photocatalytic degradation (a) phenol (b) $o$-chlorophenol.

intermediates formed were chlorohydroquinone (concentration ranges from 0.2 to $0.5 \mathrm{mg} / \mathrm{L}$ ), catechol concentration ranges from 1 to $16 \mathrm{mg} / \mathrm{L}$ ), and hydroxyhydroquinol concentration ranges from $(0.2$ to $0.7 \mathrm{mg} / \mathrm{L})$.

3.4. Possible Reaction Mechanism. The reaction taking place at the surface of the photocatalyst is a redox reaction. The photocatalytic degradation of phenol and $o$-chlorophenol takes place via ${ }^{\bullet} \mathrm{OH}$ radical attack. Several intermediates are formed during the process of degradation. Generally, after the attachment of two $\mathrm{OH}$ groups, the aromatic ring breaks. The subsequent products are rapidly oxidized to
$\mathrm{CO}_{2}$ and $\mathrm{H}_{2} \mathrm{O}$, as evidenced by the absence of aliphatic moieties [15]. In case of phenol, the ${ }^{\bullet} \mathrm{OH}$ radical mainly attacks the ortho and para position of benzene ring and hence catechol and hydroquinol were the major intermediates formed. Generally, intermediates with 2 or at the most $3 \mathrm{OH}$ groups were observed after which the cleavage of ring takes place.

In case of $o$-chlorophenol, the two main reaction pathways are ortho addition resulting into formation of catechol and hydroxyhydroquinol and para addition which results in the formation of chlorohydroquinol as the major intermediates.

\section{Comparative Evaluation of Photodegradation of Phenolics}

In general the photocatalytic degradation rate of $o$ chlorophenol is higher as compared to phenol and may be attributed to the following.

(1) The adsorption of $o$-chlorophenol is more as compared to phenol which in turn leads to high photodegradation rate.

(2) The aryl-Cl bond is a weak bond and it is cleaved with relative ease which further facilitates the attack of ${ }^{\bullet} \mathrm{OH}$ radical.

\section{Mechanistic Aspects of the Photocatalytic Degradation of Phenolics}

A possible mechanistic pathway illustrating the various sequence of events taking place at the semiconductor photocatalyst is as follows.

(1) Irradiation of the semiconductor photocatalyst leads to the generation of electron/hole pair which can either recombine or dissociate to give a conduction band electron and valence band hole.

(2) Oxygen that is sparged is omnipresent on the surface of the catalyst and acts as an electron acceptor whereas $\mathrm{OH}^{-}$groups and $\mathrm{H}_{2} \mathrm{O}$ molecules available as electron donors interact with the photogenerated hole to yield highly reactive ${ }^{\bullet} \mathrm{OH}$ radicals.

(3) The phenol molecule reacts with the highly reactive hydroxyl radical and according to the substitution rule the $\cdot \mathrm{OH}$ radical attacks the ortho and para position of the aromatic ring due to the existing $\mathrm{OH}$ group on it.

(4) The major intermediates in case of phenol are catechol and hydroquinol.

(5) After the addition of 2-3 OH groups on the aromatic ring, the cleavage of ring takes place leading to further mineralization.

(6) In case of $o$-chlorophenol, the ${ }^{\bullet} \mathrm{OH}$ radical attacks at ortho position leading to the formation of hydroxyhydroquinol, and the cleavage of aryl- $\mathrm{Cl}$ and further 
addition of ${ }^{\bullet} \mathrm{OH}$ radical lead to the formation of chlorohydroquinol.

(7) Subsequent reactions further lead to mineralization of intermediates into carbondioxide and water.

\section{Conclusions}

In the present study, we have explored the photo-oxidation properties of $\mathrm{N}$-doped mesoporous titania in photodegradation of phenolics under visible light. It was observed that the catalyst shows significant activity in the solar radiation as compared to artificial light. It was seen that initial $\mathrm{pH}$ and coexisting ions have a significant influence on the photocatalytic degradation rates. Maximum degradation was observed at neutral $\mathrm{pH}$ while the presence of coions has a detrimental effect on the degradation rates in case of both phenol and $o$-chlorophenol. The detailed studies pertaining to reuse and regeneration of the photocatalyst will be investigated in the latter part of this research work. Further improvement in photocatalytic activity of N-doped mesoporous titania is envisaged by codoping with nonmetal or metal ions.

\section{Acknowledgments}

Financial support from Ministry of Environment and Forest (MOEF), government of India, and Network Project (NWP0022) is greatly acknowledged. The authors are also thankful to NCL, Pune and JNARDDC, Nagpur for their cooperation during various characterization analyses. One of the authors P. A. Mangrulkar, would also take the opportunity to sincerely acknowledge the Council of Scientific and Industrial Research (CSIR) India for granting the Senior Research Fellowship. Thanks are also due to Mr. Pradeep Kumar Doggali for his cooperation and invaluable inputs.

\section{References}

[1] L. H. Keith and W. A. Telliard, "Priority pollutants. I. A perspective view," Environmental Science and Technology, vol. 13, no. 4, pp. 416-423, 1979.

[2] U. I. Gaya and A. H. Abdullah, "Heterogeneous photocatalytic degradation of organic contaminants over titanium dioxide: a review of fundamentals, progress and problems," Journal of Photochemistry and Photobiology C, vol. 9, no. 1, pp. 1-12, 2008.

[3] A. Fujishima and K. Honda, "Electrochemical photolysis of water at a semiconductor electrode," Nature, vol. 238, no. 5358, pp. 37-38, 1972.

[4] R. Asahi, T. Morikawa, T. Ohwaki, K. Aoki, and Y. Taga, "Visible-light photocatalysis in nitrogen-doped titanium oxides," Science, vol. 293, no. 5528, pp. 269-271, 2001.

[5] H. Irie, Y. Watanabe, and K. Hashimoto, "Nitrogenconcentration dependence on photocatalytic activity of $\mathrm{TiO}_{2-x} \mathrm{~N}_{x}$ powders," Journal of Physical Chemistry B, vol. 107, no. 23, pp. 5483-5486, 2003.

[6] C. Burda, Y. Lou, X. Chen, A. C. S. Samia, J. Stout, and J. L. Gole, "Enhanced nitrogen doping in $\mathrm{TiO}_{2}$ nanoparticles," Nano Letters, vol. 3, no. 8, pp. 1049-1051, 2003.
[7] D. G. Shchukin and R. A. Caruso, "Template synthesis and photocatalytic properties of porous metal oxide spheres formed by nanoparticle infiltration," Chemistry of Materials, vol. 16, no. 11, pp. 2287-2292, 2004.

[8] P. Yang, D. Zhao, D. I. Margolese, B. F. Chmelka, and G. D. Stucky, "Generalized syntheses of large-pore mesoporous metal oxides with semicrystalline frameworks," Nature, vol. 396, no. 6707, pp. 152-155, 1998.

[9] M. Niederberger, M. H. Bartl, and G. D. Stucky, "Benzyl alcohol and titanium tetrachloride-a versatile reaction system for the nonaqueous and low-temperature preparation of crystalline and luminescent titania nanoparticles," Chemistry of Materials, vol. 14, no. 10, pp. 4364-4370, 2002.

[10] H. Shibata, T. Ogura, T. Mukai, T. Ohkubo, and H. Sakai, "Direct synthesis of mesoporous titania particles having a crystalline wall," Journal of the American Chemical Society, vol. 127, no. 47, pp. 16396-16397, 2005.

[11] G. Cook, P. L. Timms, and C. Göltner-Spickermann, "Exact replication of biological structures by chemical vapor deposition of silica," Angewandte Chemie International Edition, vol. 42, no. 5, pp. 557-559, 2003.

[12] V. Valtchev, M. Smaihi, A. C. Faust, and L. Vidal, "Biomineralsilica-induced zeolitization of Equisetum Arvense," Angewandte Chemie International Edition, vol. 42, no. 24, pp. 27822785, 2003.

[13] S. A. Davis, S. L. Burkett, N. H. Mendelson, and S. Mann, "Bacterial templating of ordered macrostructures in silica and silica-surfactant mesophases," Nature, vol. 385, no. 6615, pp. 420-423, 1997.

[14] B. Chi, L. Zhao, and T. Jin, "One-step template-free route for synthesis of mesoporous N-doped titania spheres," Journal of Physical Chemistry C, vol. 111, no. 17, pp. 6189-6193, 2007.

[15] T. Horikawa, M. Katoh, and T. Tomida, "Preparation and characterization of nitrogen-doped mesoporous titania with high specific surface area," Microporous and Mesoporous Materials, vol. 110, no. 2-3, pp. 397-404, 2008.

[16] S. P. Kamble, S. B. Sawant, and V. G. Pangarkar, "Batch and continuous photocatalytic degradation of benzenesulfonic acid using concentrated solar radiation," Industrial and Engineering Chemistry Research, vol. 42, no. 26, pp. 6705-6713, 2003.

[17] M. M. Joshi, N. K. Labhsetwar, P. A. Mangrulkar, S. N. Tijare, S. P. Kamble, and S. S. Rayalu, "Visible light induced photoreduction of methyl orange by $\mathrm{N}$-doped mesoporous titania," Applied Catalysis A, vol. 357, no. 1, pp. 26-33, 2009.

[18] H. Fei, Y. Liu, Y. Li et al., "Selective synthesis of borated meso-macroporous and mesoporous spherical $\mathrm{TiO}_{2}$ with high photocatalytic activity," Microporous and Mesoporous Materials, vol. 102, no. 1-3, pp. 318-324, 2007.

[19] A. Mills, R. H. Davies, and D. Worsley, "Water purification by semiconductor photocatalysis," Chemical Society Reviews, vol. 22, no. 6, pp. 417-425, 1993.

[20] D. S. Bhatkhande, V. G. Pangarkar, and A. C. M. Beenackers, "Photocatalytic degradation for environmental applicationsa review," Journal of Chemical Technology and Biotechnology, vol. 77, no. 1, pp. 102-116, 2001. 


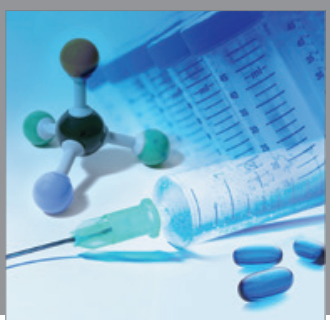

International Journal of

Medicinal Chemistry

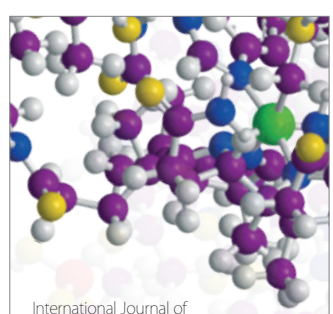

Carbohydrate Chemistry

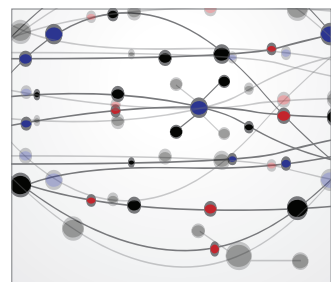

The Scientific World Journal
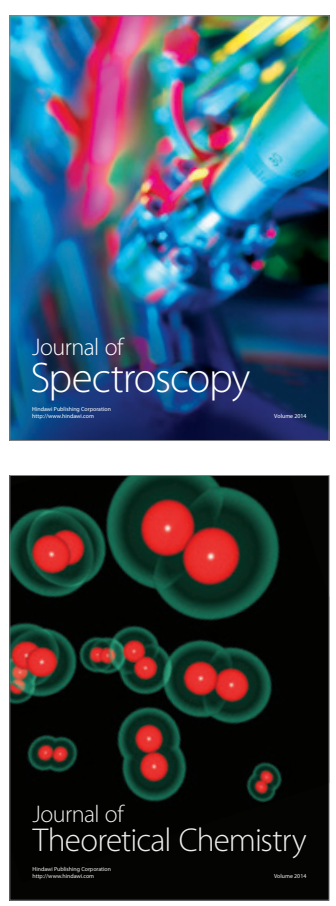
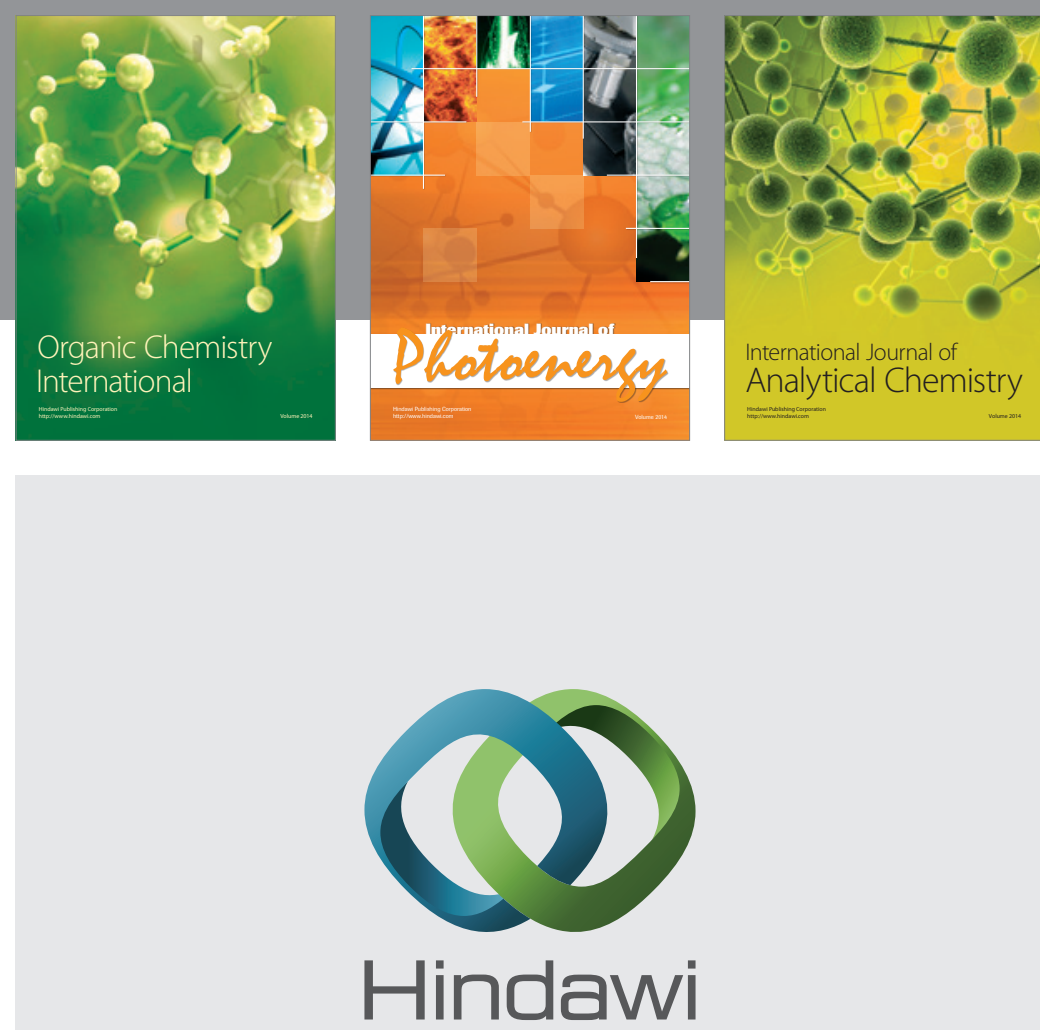

Submit your manuscripts at

http://www.hindawi.com
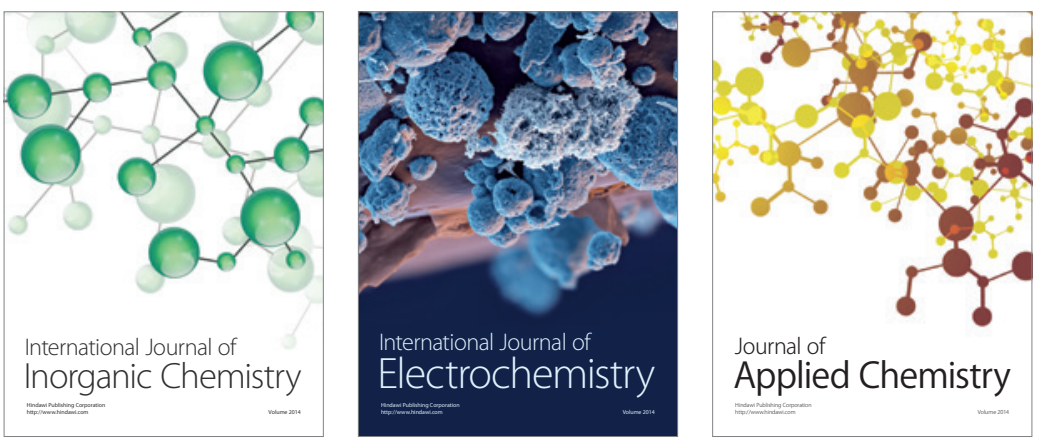

Journal of

Applied Chemistry
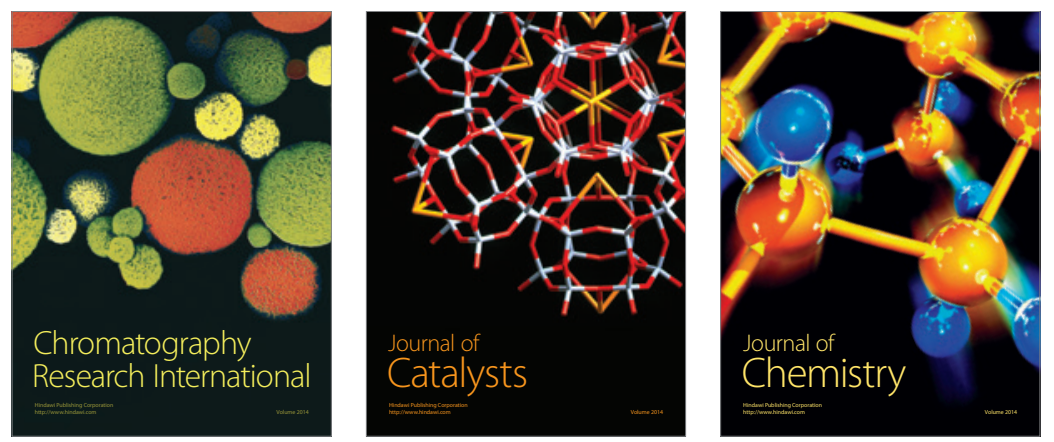
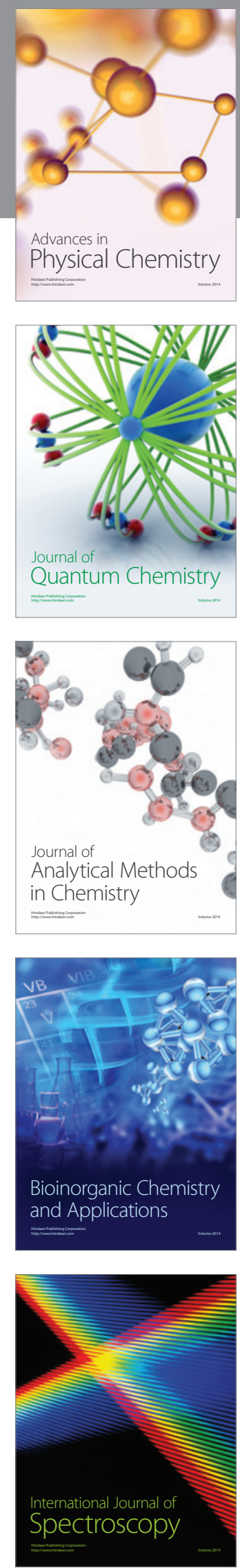